\title{
Correction to: Identification of the meiotic toolkit in diatoms and exploration of meiosis-specific SPO11 and RAD51 homologs in the sexual species Pseudo- nitzschia multistriata and Seminavis robusta
}

Shrikant Patil', Sara Moeys ${ }^{2,3,4}$, Peter von Dassow ${ }^{5,6}$, Marie J. J. Huysman 2,3,4, Daniel Mapleson? Lieven De Veylder ${ }^{3,4}$, Remo Sanges ${ }^{1}$, Wim Vyverman ${ }^{2}$, Marina Montresor ${ }^{1}$ and Maria Immacolata Ferrante ${ }^{1 *}$

Correction to: BMC Genomics

https://doi.org/10.1186/s12864-015-1983-5

Following the publication of this article [1], the authors reported that the link to Additional file 11 linked to the wrong set of data. The correct supplementary data is provided in this Correction article (Additional file 11).

\section{Additional file}

Additional file 11: HMM profiles used for Hmmsearch. (ZIP $1469 \mathrm{~kb}$ )

\section{Author details}

${ }^{1}$ Stazione Zoologica Anton Dohrn, Villa Comunale 1, 80121 Naples, Italy.

${ }^{2}$ Department of Biology, Protistology and Aquatic Ecology, Ghent University, 9000 Ghent, Belgium. ${ }^{3}$ Department of Plant Systems Biology, Flanders Institute for Biotechnology (VIB), 9052 Ghent, Belgium. ${ }^{4}$ Department of Plant Biotechnology and Bioinformatics, Ghent University, 9052 Ghent, Belgium.

${ }^{5}$ Facultad de Ciencias Biológicas, Instituto Milenio de Oceanografía, Pontificia Universidad Católica de Chile, Santiago, Chile. ${ }^{6} U M I$ 3614, Evolutionary Biology and Ecology of Algae, CNRS-UPMC Sorbonne Universités, PUCCh, UACH, Station Biologique de Roscoff, Roscoff, France. ${ }^{7}$ The Genome Analysis Centre (TGAC), Norwich Research Park, Norwich NR4 7UH, UK.

Received: 27 June 2019 Accepted: 27 June 2019

Published online: 05 July 2019

\section{Reference}

1. Patil $\mathrm{S}$, et al. Identification of the meiotic toolkit in diatoms and exploration of meiosis-specific SPO11 and RAD51 homologs in the sexual species Pseudo-nitzschia multistriata and Seminavis robusta. BMC Genomics. 2015;16: 930. https://doi.org/10.1186/s12864-015-1983-5.

* Correspondence: mariella.ferrante@szn.it

'Stazione Zoologica Anton Dohrn, Villa Comunale 1, 80121 Naples, Italy

Full list of author information is available at the end of the article

(c) The Author(s). 2019 Open Access This article is distributed under the terms of the Creative Commons Attribution 4.0 International License (http://creativecommons.org/licenses/by/4.0/), which permits unrestricted use, distribution, and reproduction in any medium, provided you give appropriate credit to the original author(s) and the source, provide a link to the Creative Commons license, and indicate if changes were made. The Creative Commons Public Domain Dedication waiver (http://creativecommons.org/publicdomain/zero/1.0/) applies to the data made available in this article, unless otherwise stated. 